\title{
Fluorescence Activated Cell Sorting (FACS) of CK15 Cells in Canine Hair Follicular Tissue
}

\author{
N. Hemavathi ${ }^{1}$, Sabiha Hayath Basha ${ }^{2 *}$, S. Usha Kumary ${ }^{1}$ and R. Sivashankar ${ }^{3}$ \\ ${ }^{1}$ Department of Veterinary Anatomy, Madras Veterinary College, \\ TANUVAS, Chennai-600 007, Tamil Nadu, India \\ $2^{2 *}$ Centre for Stem Cell Research and Regenerative Medicine, Madras Veterinary College, \\ TANUVAS, Chennai-600 007, Tamil Nadu, India \\ ${ }^{3}$ Department of Veterinary Surgery and Radiology, Madras Veterinary College, \\ TANUVAS, Chennai-600 007, Tamil Nadu, India \\ *Corresponding author
}

Keywords

cHFSCs, CK15, FACS, Stem cells,

Article Info

Accepted:

20 January 2020

Available Online:

10 February 2020

\section{A B S T R A C T}

Hair follicle is an ideal system for studying the biology and regulation of adult stem cells. Multipotent stemness of the canine hair follicle stem cells (cHFSCs) were detected by immunostaining the cells with positive HFSC surface markers like Anti-cytokeratin-15 (CK15) and CD200. In this study, canine hair follicular cells were cultured in Williams'E media supplemented with growth factors. The primary cultures of the hair follicles were subjected to Fluorescence Activated Cell Sorting (FACS) and then cells were immunostained with CK15 and DAPI. In primary culture, $18.28 \%$ of cells were positive for CK15 and sorted out by FACS. The positive expression of CK15 transcription factor was observed with DAPI as a counter stain in the in-vitro cultured cHFSCs. These results indicated that the cells in the canine hair follicular bulge region possess the stemness and act as a precursor and involved in hair cycle.

\section{Introduction}

Hair follicle is an ideal system for studying the biology and regulation of adult stem cells (Soteriou et al., 2016). The hair follicle stem cells (HFSCs) were located in the hair follicle outer root sheath (ORS). They were adult stem cells with unlimited self-renewal capacity and multiple differentiation probabilities (Shen et al., 2017). In the growing phase (anagen), hair follicles would undergo rapid epithelial cell division and executed timed differentiation programmes. Then as growth stopped (catagen), most follicles regressed into structures that resembled immature developing follicles after 
which they underwent into a period of mitotic quiescence (telogen). Stem cells were at the core of these dynamic events that included a new burst of activity and further morphogenetic remodelling as the follicle grew again at the start of a new anagen phase (Waters et al., (2007).

Hair follicle stem cells of rat vibrissa were cultured from their explants and colonies were made up of compactly arranged, small round cells (Reynolds and Jahoda, 1991). Colonies formed by human keratinocytes could be classified into two morphological types, depending on the growth potential of the founding cell.

Progressively growing colonies were constituted of small proliferative cells and they called as meroclones or holoclones. Human hair follicular and epidermal derived keratinocytes showed that the expression of CD200, K15, CD34, and CD271 were nearly undetectable in both groups, no apparent differences were observed in the expression of CD29, CD49f, K1, and K14 between the two groups (Inoue et al., 2009).

In general, immuno-phenotyping is mostly performed by flowcytometry, as this technique allows for a rapid identification of cells by the presence of specific cell surface markers. These cell surface markers typically belong to the 'cluster of differentiation' (CD) (de Schauwer et al., 2011). Specific surface markers like CD200, K15, CD34 and CD271 were useful antibodies for characterizing freshly isolated human follicular epithelial cells in diverse stages of differentiation (Ohyama et al., 2006).

Gilanchi et al., (2014) used flow cytometry analysis to assess the purity of HFSCs cultures with nestin, CD34 and K15 antibodies and it showed positive for nestin, CD34 antibodies and negative for K15 antibody. Flow cytometry analysis of HFSCs from human scalp showed the percentage of HFSCs expressing CD200 and K15 which were about $65.20 \pm 3.16$ and $72.07 \pm 6.62$ respectively. This indicated that the K15 and CD200 were best positive markers for human bulge cells (Hilmi et al., 2013). Hence present work carried out to assess the phenotyping of cHFSCs isolated from the bulge with Anticytokeratin 15 (CK15) marker.

\section{Materials and Methods}

Canine hair follicle stem cells were isolated by separating the hair follicles from canine skin and digested them into trypsin/EDTA for obtaining single cell suspension. They were cultured in William's E medium or DMEM supplemented with $10 \%$ fetal bovine serum, and $10 \mathrm{ng} / \mathrm{ml}$ of epidermal growth factor, $5 \mathrm{ng} / \mathrm{ml}$ of insulin growth factor, $2 \%$ of antibiotic and antimycotic solution and $1 \%$ of amphotericin $\mathrm{B}$ in a humidified atmosphere at $37^{\circ} \mathrm{C}$ with $5 \% \mathrm{CO}_{2}$.

\section{Fluorescence activated cell sorting (FACS):}

Primary culture cells were dissociated from culture plates and checked for viability and total cell number. Viability percentage of cells should not be less than $90 \%$ for fluorescent activated cell sorting. About $1-5 \times 10^{6} \mathrm{Cells} / \mathrm{ml}$ were taken in two eppendorf tubes, and pellet was resuspended in FACS buffer (ice cold DPBS, 10\% Fetal Bovine Serum (FBS), one per cent sodium azide) mixed thoroughly.

Then $100 \mu 1$ of cell suspension was taken into each tube and $100 \mu \mathrm{l}$ of Primary antibody Anti-Cytokeratin 15 (LHK15) (ab80522) $(5 \mu \mathrm{g} / \mathrm{ml})$ in $3 \%$ BSA was added and tubes were covered with aluminium foil and incubated at $4^{\circ} \mathrm{C}$ for 30 minutes in dark. After incubation, cells were washed three times by centrifugation at $400 \mathrm{~g}$ for five minutes and resuspended in ice cold PBS and cell pellets 
were incubated with $100 \mu \mathrm{l}$ of FITC conjugated secondary antibody in 1:1000 dilution for 30-45 minutes at room temperature in dark area. Cells were washed three times by ice cold PBS. Cell pellet were resuspended in FACS buffer and observed in FACS, forward and side scatters were plotted.

\section{Immunocytochemistry}

The cells were washed with Dulbecco's phosphate buffered saline (DPBS) twice and the cells were fixed with $4 \%$ paraformaldehyde for 5 minutes at room temperature (RT) and washed with DPBS. Fixed cells were permeabilized by $1000 \mu \mathrm{l} /$ well of $0.1 \%$ Triton $\mathrm{X}-100$ in DPBS for 5-10 minutes in RT and culture plates were washed. $400 \mu \mathrm{l}$ of $8 \%$ blocking buffer was added to the well and plates were covered with aluminium foil to prevent exposure to light and stored at RT for 25 minutes.

Blocking buffer was removed and cells were incubated with $250 \mu \mathrm{l}$ of $5 \mu \mathrm{g} / \mathrm{ml}$ concentration of primary antibody Anti-Cytokeratin15 at $4^{\circ} \mathrm{C}$ for overnight. Primary antibody was then removed from wells and $250 \mu \mathrm{l}$ of secondary antibody (Goat Anti-mouse IgG FITC conjugated) of 1:1000 dilutions were added to the wells and covered with aluminium foil, incubated for one hour in RT and washed. 4'6- diamino-2-phenylindole (DAPI) with fluoroshield drops were added to the wells and covered with aluminium foil and incubated for $5 \mathrm{~min}$ in RT. The cells were viewed under fluorescence microscope.

\section{Statistical analysis}

Statistical calculations were recorded according to the standard statistical procedures recommended by Snedecor and Cochran (1994). All the data were expressed as mean \pm standard error (S.E).

\section{Results and Discussion}

\section{Fluorescence activated cell sorting (FACS):}

Primary culture cells were analyzed by FACS, to assess the percentage of cHFSCs which were positive for Anti-Cytokeratin 15 (CK15) surface marker from the whole population. In primary culture, the mean percentage value for CK15+ surface marker was found to be $18.28 \%$ (Figure-1). In the primary culture of cHFSCs, about $112.67 \pm 42.36$ numbers of cells were positively stained for CK15 among the total cells of $616.33 \pm 51.02$ counted (Plate-1). A similar observation has been made by Kobayashi et al., (2009) in canine where 29.2 percentage of total population of cHFSCs were positive for CK15. Flow cytometry analysis of human HFSC culture showed $65.20 \pm 3.16$ per cent and $72.07 \pm$ 6.62 per cent of cells were positive for CD200 and CK15 surface markers respectively (Hilmi et al., 2013). Gentile et al., (2017) separated $3728.5 \pm 664.5$ cells from human scalp tissue and found $2.6 \pm 0.3$ percentage of cells were positive for CD200.

De Castro et al., (2018) reported that the flow cytometry of fetal and adult canine skin culture (P0) cells showed that 12.7 percent and 29 per cent of cells were positive for CD34 respectively. Multicolor flow cytometry analysis showed a well demarcated $\mathrm{CD}_{200^{+}}$population in freshly isolated follicular cells, but not freshly isolated epidermal cells. To focus on bulge stem cells, they analyzed $\mathrm{CD}_{200^{+}} \mathrm{CD}^{-} 4^{-}$cells; K15

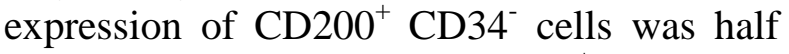
positive and half negative. $\mathrm{K} 15^{+}$and $\mathrm{K} 15^{-}$ cells were distinct from each other by cell size; the $\mathrm{CD} 200^{+} \mathrm{CD}^{-} 4^{-} \mathrm{K} 15^{+}$population corresponded to basal bulge cells and was significantly larger in cell size than CD200 CD $34^{-} \mathrm{K} 15^{-}$population which was considered to be the suprabasal bulge cells. A major portion of $\mathrm{CD}_{3} 4^{+}$cells were $\mathrm{K}_{15}{ }^{+}$(Inoue et al., 2009). 


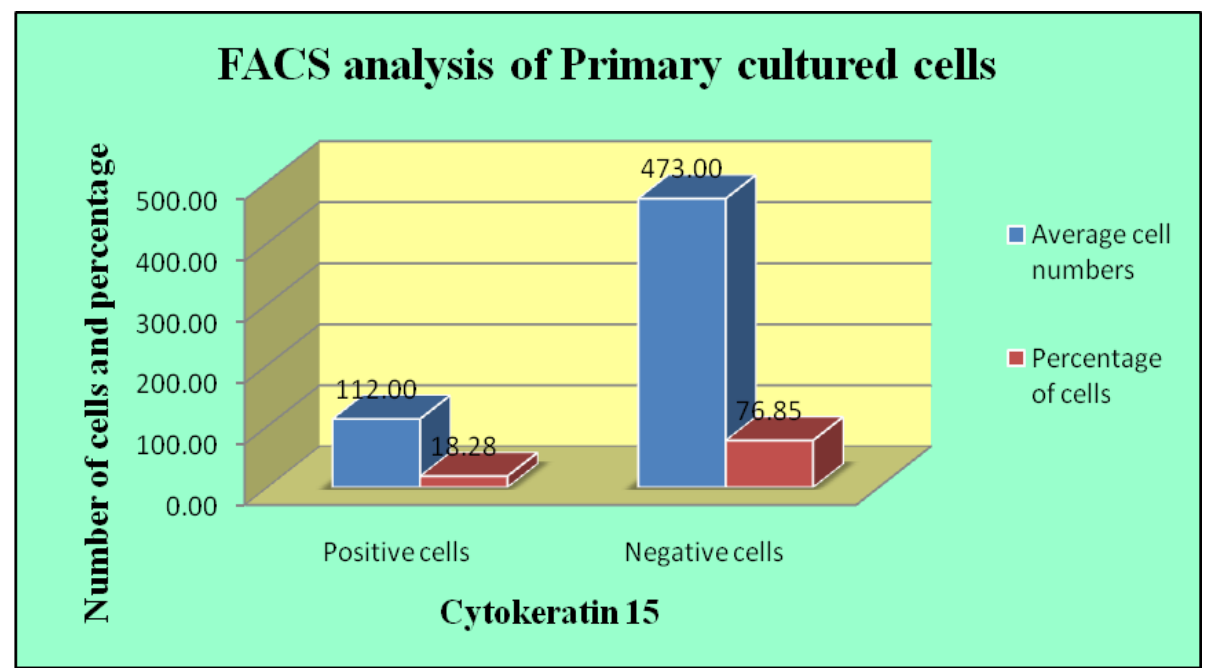

Plate.1 Histogram representing flowcytometry performed on primary cultured canine hair follicle stem cells (cHFSCs) using Cytokeratin 15 (CK15) surface marker

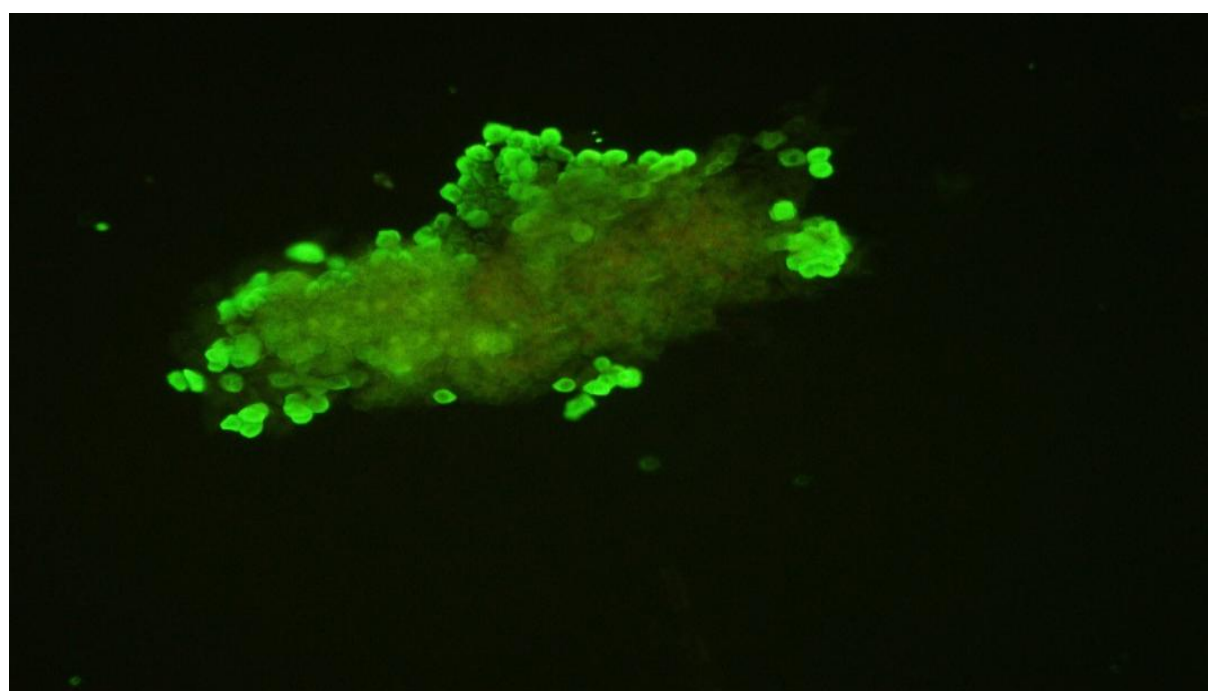

Plate.2 Photomicrograph of cHFSCs derived from culture showing positive expression for Cytokeratin $15($ CK15) surface marker $(\times 200)$

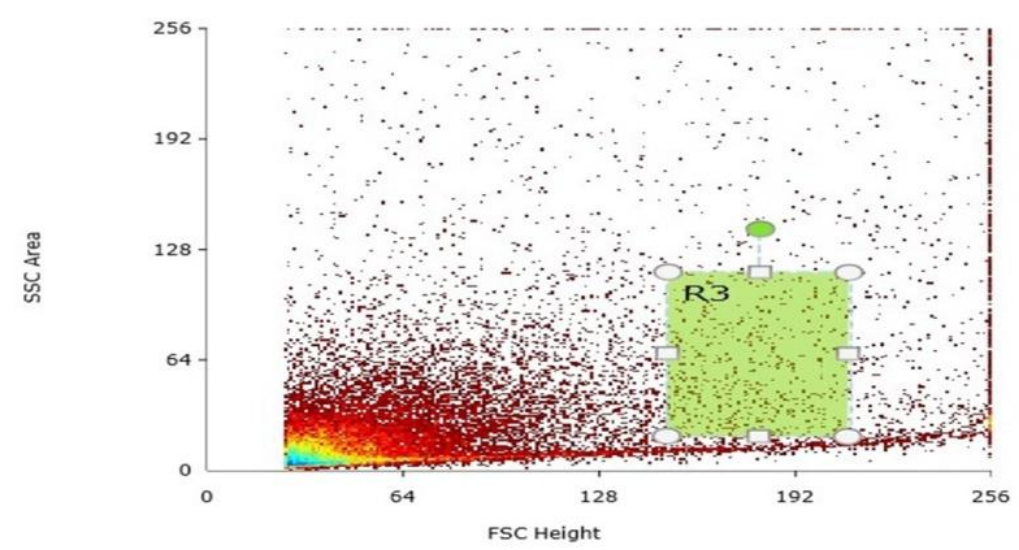




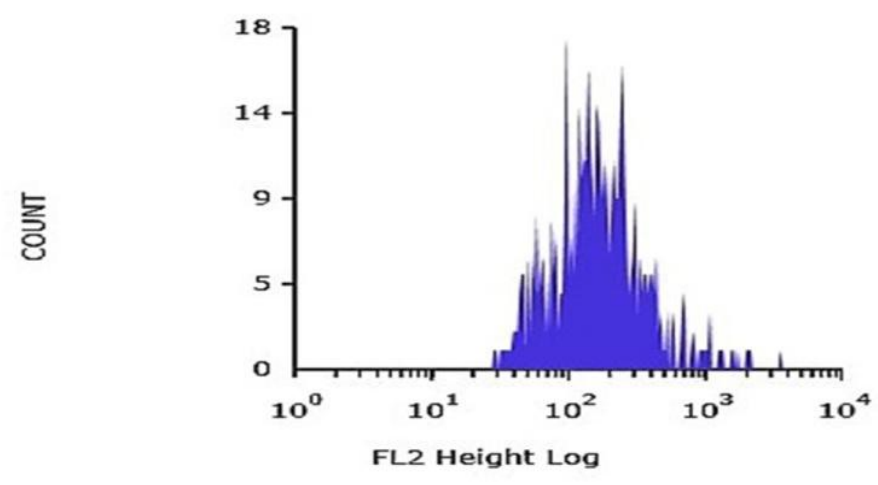

\section{Immunocytochemistry}

The primary cultured cells were larger in size with typical morphology of small flat cells with round nucleus. On day seven, about 7080 per cent confluency of cells with cobblestone appearance was observed as matching to Kobayashi et al., (2009) (Plate2). Cultured flat cHFSCs with short cytoplasmic processes were observed. The morphology of cultured cHFSCs in this study were also similar to the findings of Zhang et al., (2006) in human HFSCs, He et al., (2016) in gHFSCs.

In this protocol, the primary cultured cells of the canine hair follicle filtrate culture were immune stained with Anti-Cytokeratin 15 (CK15) and DAPI on day seven of post incubation. The expression of CK15 transcription factor and DAPI was observed as intra cytoplasmic green fluorescence and intra nuclear blue fluorescence respectively in cHFSCs from seven to14 days of cultured cells (Plate-3) as per He et al., (2016) in gHFSC and Inoue et al., (2009) and Hilmi et al., (2013) in human HFSCs along with CD200, CD34, K14, K15, CD271, and K1 markers. Shen et al., (2017) also performed immunofluorescence detection for K19 and $\beta 1$-integrin in human HFSCs. Amoh et al., (2005) reported that the pluripotent nestindriven GFP stem cells were positive for the stem cell marker CD34 but negative for CK15 and $\beta$-III tubulin.

\section{Acknowledgements}

We are thankful to Dean, Madras Veterinary College, Department of Surgery and Radiology and Centre for Stem Research and Regenerative Medicine, Madras Veterinary College, TANUVAS for providing necessary facilities to carry out the research work

\section{References}

Amoh, Y., Li, L., Campillo, R., Kawahara, K., Katsuoka, K., Penman, S. and Hoffman, R. M. 2005. Implanted hair follicle stem cells form Schwann cells that support repair of severed peripheral nerves. Proc. Natl. Acad. Sci. 102: 17734-17738.

De Castro, R.V., Tavares, M.R., Bressan, F.F., Pieri, N.C., Hill, A.B.T., Souza, A.F., da RN Cruz, Martins, D.S., Ambrósio, C.E., Meirelles, F.V. and Garcia, J.M. 2018. In vitro identification of a stem cell population from canine hair follicle bulge region. Tissue Cell. 50: 43-50.

De Schauwer, C., Meyer, E., Van de Walle, G.R. and Van Soom, A. 2011. Markers of stemness in equine mesenchymal stem cells: a plea for uniformity. Theriogenology. 75(8): 1431-1443.

Gilanchi, S., Esmaeilzade, B., Eidi, A., Barati, M., Mehrabi, S., Ghoroghi, F.M. and Nobakht, M. 2014. Neuronal differentiation of rat hair follicle stem 
cells: the involvement of the neuroprotective factor Seladin-1 (DHCR24). Iranian biomedical journal. 18(3): 136.

Gentile, P., Scioli, M.G., Bielli, A., Orlandi, A. and Cervelli, V. 2017. Stem cells from human hair follicles: first mechanical isolation for immediate autologous clinical use in androgentic alopecia and hair loss. Stem Cell Investig. 4: 58.

He, N., Dong, Z., Tao, L., Zhao, S., Bou, S. and Liu, D. 2016. Isolation and characterization of hair follicle stem cells from Arbas Cashmere goat. Cytotechnology. 68: 2579-2588.

Hilmi, A.B.M., Halim, A.S., Noor, N.M., Lim, C.K., Idris, Z., Pohchi, A., Asma, H., Wahab, S.F.A., Tiede, S. and Paus, R. 2013. A simple culture method for epithelial stem cells derived from human hair follicle. Cent. Eur. J. Biol. 8(5): 432-439.

Inoue, K., Aoi, N., Sato, T., Yamauchi, Y., Suga, H., Eto, H., Kato, H., Araki, J. and Yoshimura, K. 2009. Differential expression of stem-cell-associated markers in human hair follicle epithelial cells. Lab. Investig. 89(8): 844.

Kobayashi, T., Shimizu, A., Nishifuji, K., Amagai, M., Iwasaki, T. and Ohyama, M. 2009. Canine hair-follicle keratinocytes enriched with bulge cells have the highly proliferative characteristic of stem cells. Vet. Dermatol. 20(5-6): 338-346.

Ohyama, M., Terunuma, A., Tock, C.L.,
Radonovich, M.F., Pise-Masison, C.A., Hopping, S.B., Brady, J.N., Udey M.C. and Vogel, J.C. 2006. Characterization and isolation of stem cell-enriched human hair follicle bulge cells. J. Clin. Investig. 116: 249-260.

Reynolds, A.J. and Jahoda, C.A. 1991. Hair follicle stem cells? A distinct germinative epidermal cell population is activated in vitro by the presence of hair dermal papilla cells. J. Cell. Sci. 99: 373-385.

Shen, Q., Yu, W., Fang, Y., Yao, M. and Yang, P. 2017. Beta-catenin can induce hair follicle stem cell differentiation into transit-amplifying cells through cmyc activation. Tissue Cell. 49(1): 2834.

Snedecor, G.W. and Cochran, W.G. 1994. Statistical methods, $8^{\text {th }}$ edn. Alliliated East.

Soteriou, D., Kostic, L., Sedov, E., Yosefzon, Y., Steller, H. and Fuchs, Y. 2016. Isolating hair follicle stem cells and epidermal keratinocytes from dorsal mouse skin. JoVE. 110: 53931.

Waters, J.M., Richardson, G.D. and Jahoda, C.A. 2007. Hair follicle stem cells. J. Seminars in cell \& developmental biology, 18(2): 245-254.

Zhang, Y., Xiang, M., Wang, Y., Yan, J., Zeng, Y., Yu, J. and Yang, T. 2006. Bulge cells of human hair follicles: segregation, cultivation and properties. Colloids and Surfaces B: Biointerfaces. 47(1): 50-56.

\section{How to cite this article:}

Hemavathi. N, Sabiha Hayath Basha, S. Usha Kumary and Sivashankar. R. 2020. Fluorescence Activated Cell Sorting (FACS) of CK15 Cells in Canine Hair Follicular Tissue. Int.J.Curr.Microbiol.App.Sci. 9(02): 2929-2934. doi: https://doi.org/10.20546/ijcmas.2020.902.334 